DR. JOHN M. LILESTRAND (Orcid ID : 0000-0001-6562-2458)

PROF. PIRKKO J. PUSSINEN (Orcid ID : 0000-0003-3563-1876)

Article type : Original Scientific Article

\title{
Carotid artery calcification in panoramic radiographs associates with oral infections and mortality
}

S. Paju ${ }^{1}$, M. Pietiäinen ${ }^{1}$, J.M. Liljestrand ${ }^{1}$, L. Lahdentausta ${ }^{1}$, A. Salminen ${ }^{1}$, E. Kopra ${ }^{1}$, P. Mäntylä ${ }^{2}$, K. Buhlin ${ }^{1,3}$, S. Hörkkö ${ }^{4,5}$, J. Sinisalo ${ }^{6}$, and P.J. Pussinen ${ }^{1}$

${ }^{1}$ Department of Oral and Maxillofacial Diseases, University of Helsinki and Helsinki University Hospital, Helsinki, Finland; 2 Institute of Dentistry, University of Eastern Finland and Kuopio University Hospital, Oral and Maxillofacial Diseases, Kuopio, Finland; ${ }^{3}$ Division of Periodontology, Department of Dental Medicine, Division of Oral Diseases, Karolinska Institutet, Huddinge, Sweden; ${ }^{4}$ Research Unit of Biomedicine, Medical Microbiology and Immunology, Faculty of Medicine, University of Oulu, Oulu, Finland; ${ }^{5}$ Medical Research Center and Nordlab Oulu, University Hospital and University of Oulu, Oulu, Finland; ${ }^{6}$ Heart and Lung Center, Helsinki University Hospital and Helsinki University, Helsinki, Finland.

Running title: CAC and apical periodontitis

Keywords: antibodies; cardiovascular diseases; oral microbiota; panoramic tomography; saliva; subgingival plaque

\section{Corresponding author:}

This article has been accepted for publication and undergone full peer review but has not been through the copyediting, typesetting, pagination and proofreading process, which may lead to differences between this version and the Version of Record. Please cite this article as doi: 10.1111/IEJ.13394

This article is protected by copyright. All rights reserved 


\section{P. Pussinen}

Department of Oral and Maxillofacial Diseases, P.O. Box 63, Fl-00014 University of Helsinki, Helsinki, Finland.

Email: pirkko.pussinen@helsinki.fi

This article is protected by copyright. All rights reserved 


\section{Abstract}

Aim To study the prevalence of carotid artery calcification (CAC) in relation to apical and marginal periodontitis, subgingival dysbiotic bacterial species and serum and saliva immune responses against them. In addition, the aim was to analyze the association of CAC with angiographically verified coronary artery disease (CAD) and mortality.

Methodology In the present random Parogene cohort, the patients had an indication for coronary angiography. Apical and marginal periodontitis were diagnosed in clinical and radiographic oral examinations, and CAC on panoramic radiographies $(n=492)$. Presence and severity of CAD were registered from angiography. Subgingival dysbiotic bacterial species were quantitated using checkerboard DNA-DNA-hybridization, and serum and saliva antibody levels were determined by immunoassays. The cohort was followed-up for 10 years or until death (median 9.9, range 0.2110.4) via linkage to the national death register. The statistical models were adjusted for age, gender, smoking, hypertension, diabetes, and dyslipidemia.

Results A total of $102(20.7 \%)$ patients had detectable CAC, which was moderate in $81(16.4 \%)$ and severe in $21(4.3 \%)$. CAC was associated (OR, 95\% $\mathrm{Cl}$ ) with severe apical periodontitis $(2.25,1.15-4.41)$, root canal fillings $(1.15,1.04-1.26)$, alveolar bone loss $(2.66,1.21-5.84)$, severe periodontal inflammation $(2.23,1.11-4.47)$, high level of gram-negative subgingival species $(2.73$, 1.34-5.50), saliva IgG against dysbiotic species (1.05, 1.01-1.10 / unit), and severe (2.58, 1.36$4.90)$ and chronic $(2.13,1.15-3.93)$ CAD. A total of 105 (20.7\%) patients died during the follow-up and $53(10.4 \%)$ deaths were because of cardiovascular diseases (CVD). Severe CAC predicted worse survival with HRs $(95 \% \mathrm{Cl})$ of $3.08(1.58-6.06)$ for all-cause and $3.43(1.42-8.25)$ for CVD death.

Conclusions CAC on panoramic tomography was associated with i) apical and marginal periodontitis and dysbiotic bacterial species giving rise to an immunological response, and with ii) severe, chronic CAD and increased mortality. The results further emphasize the role of oral infections in CAD and the importance of referring a patient with CAC for a cardiovascular evaluation.

This article is protected by copyright. All rights reserved 


\section{Introduction}

Carotid artery calcification (CAC) can be identified and even graded on panoramic dental radiographs of the maxilla and mandible (Friedlander 1995). Just as with increased carotid artery intima-media thickness, CAC may be a sign of the broader condition of atherosclerosis. In casecontrol studies, patients with CAC were more likely to demonstrate extended calcifications in abdominal aorta (Friedlander et al. 2015), aortic arch (Friedlander et al. 2014), and kidneys (Yeluri et al. 2015). Furthermore, patients with CAC suffer more often from stroke and ischemic heart disease (Bengtsson et al. 2019). According to a meta-analysis, calcifications observed with CT-scans, plain radiography, or ultrasound predict cardiovascular events and mortality (Rennenberg et al. 2009). In literature reviews, panoramic radiographs had a variable sensitivity, but acceptable specificity for detecting CAC (Khosropanah et al. 2009, Alves et al. 2014, Bengtsson et al. 2014). Therefore, the patients with CAC on dental radiographs should be referred for cardiovascular evaluation (Friedlander \& Cohen 2007, Gustafsson et al. 2018, Bengtsson et al. 2019).

The association of marginal periodontitis with several systemic conditions, such as cardiovascular diseases (CVD), is well-established (Lockhard et al. 2012). Apical periodontitis has also been regarded as a CVD risk factor (Liljestrand et al. 2016, Khalighinejad et al. 2016, Berlin-Broner et al. 2017). These two oral diseases share inflammatory, immunological, and microbiological profiles (Gomes et al. 2015, Pietiäinen et al. 2019) which link them to atherosclerosis through systemic inflammation (Hansson et al. 2015).

Marginal periodontitis has been associated with CAC in multiple studies (Ravon et al. 2003, Beckström et al. 2007, Kamak et al. 2015, Bengtsson et al. 2016, Gustafsson et al. 2020), while some studies suggest no significant association (Nakib et al. 2004). No studies regarding putative association between CAC and dysbiotic oral bacterial species or immune responses against them have been published. In addition, studies investigating the association between CAC and apical periodontitis or follow-up studies of patients with or without CAC in dental radiographs are scarce. The aim of the study was to investigate the prevalence of CAC visible on panoramic radiographs in a random cohort of patients undergoing coronary angiography. The following hypotheses were investigated: i) In a cross-sectional setting, CAC is associated with oral infections/inflammations, dysbiotic oral bacteria and immune response against them. ii) CAC is associated with diagnosis and severity of coronary artery disease (CAD). iii) In a longitudinal setting, CAC and mortality are associated in a 10 -year follow up.

\section{Materials and Methods}

\section{Study design}

This article is protected by copyright. All rights reserved 
Parogene, is a subpopulation of the prospective Corogene cohort which aims to identify coronary disease risk factors and genetics. The study is based on symptomatic Finnish patients $(n=5,788)$, who underwent a coronary angiography for any reason in Helsinki University Hospital between June 2006 and March 2008 (Vaara et al. 2012). The data includes information on previous medical conditions, CVD risk factors, medications, and coronary angiogram results. A random subpopulation of approximately $10 \%$ of the cohort, forming the Parogene sample, was invited to a clinical and radiographic oral examination.

The cohort has been followed-up for 10 years or until death (median 9.9, IQR 0.45, range 0.2110.4 years) with data on deaths being obtained through record linkage to the National Causes-ofDeath Register. Death due CVD was defined based on ICD-10 codes with the underlying, direct, or contributing cause of death as 100-199. This research has been conducted in full accordance with ethical principles including the Declaration of Helsinki. The Helsinki University Hospital ethics committee approved the study protocol (Dnro 106/2007), and all patients signed an informed consent. The study complies with 'strengthening the reporting of observational studies in Epidemiology' (STROBE) guidelines.

\section{Study population}

The Parogene study included 508 patients who were examined at the Institute of Dentistry, University of Helsinki, between October 2007 and May 2008 (Buhlin et al. 2011). Clinical and radiographical oral examinations were performed at least 6 weeks but no later than 5 months after the angiography. Presence or absence of carotid artery calcification (CAC) could be technically registered from $492(96.8 \%$ of the entire population) patients. Based on the angiography, symptoms and cardiac biomarkers, patients were assigned to groups of chronic CAD ( $n=181,36.8 \%)$, acute coronary syndrome (ACS) $(n=164,33.3 \%)$, and no significant CAD $(n=147,29.9 \%)$. Severity of CAD was defined as a number of arteries with $\geq 50 \%$ stenosis. The patients were considered to have hypertension, dyslipidemia or diabetes, if they had medications for these disorders. Information on smoking habits were collected by a questionnaire before the oral examination.

\section{Clinical oral examinations}

Clinical examination for detailed oral and periodontal status was performed in a standard dental office setting by two specialists in periodontology (P. M. and K. B.) (Buhlin et al. 2011). They had been inter-individually calibrated before the study. Extra oral and intra oral palpation was done to detect swelling or firmness, and oral structures were viewed for any abnormal findings, such as sinus tracts. Periodontal probing depths (PPD) were measured from six sites around each tooth with a manual periodontal probe and numbers of deepened periodontal pockets of 4-5 $\mathrm{mm}$ and $\geq 6 \mathrm{~mm}$ were recorded. Periodontal inflammation burden index $(\mathrm{PIBI})$ was calculated as [number 
of 4-5 mm pockets $+2^{*}(\geq 6 \mathrm{~mm}$ pockets)] (Lindy et al. 2008). Bleeding on probing (BOP) and possible suppuration were recorded from four sites of each tooth. PPD and BOP were calculated as proportions of sites examined.

\section{Radiographic oral examination}

Digital panoramic tomographs were taken after the clinical oral examination using ProOne unit (Planmeca Co., Helsinki, Finland). A single specialist of dental radiology analyzed the radiologic data including the prevalence of carotid artery calcification (CAC). CAC was differentiated from other calcified soft tissues and cartilage as reported earlier (Carter 2000). Calcification of any size and shape as a radiopaque nodular mass adjacent to or just below the intervertebral space between $\mathrm{C} 3$ and $\mathrm{C} 4$ in the carotid artery area was registered as CAC. Calcification could be present in left, right or both sides simultaneously and appear single or scattered (Friedlander 1995, Garoff et al. 2016). Heterogeneous areas of radiopacities on either side were graded as 'moderate CAC' and masses exceeding $10 \mathrm{~mm}$ as 'severe CAC' (Ravon et al. 2003).

The tooth with the most severe attachment loss was chosen from each dentate sextant for calculations of horizontal alveolar bone loss $(A B L)$. According to the mean of each sextant, $A B L$ was graded: i) no $A B L$; ii) mild, $A B L$ in cervical third of the root; iii) moderate, $A B L$ in the middle third of the root; and iv) from severe to total loss, $A B L$ from the apical third of the root to total $A B L$. Endodontic lesions were diagnosed from the radiographs as described in detail earlier (Liljestrand et al. 2016). The recorded findings included root canal fillings, widened periapical space indicating irreversible pulpitis or precursors for endodontic lesions (Carrotte 2004), and apical periodontitis seen as periradicular destruction in the tip of the root. An endodontic lesion score was defined to describe the severity of apical periodontitis in dentate patients (Liljestrand et al. 2016): i) no endodontic lesions; ii) moderate apical periodontitis, if $\geq 1$ widened periapical space (Huumonen et al. 2017) and/or 1 tooth with apical periodontitis was present; and iii) severe apical periodontitis in patients with $\geq 2$ teeth with apical periodontitis. Treatment of apical periodontitis was considered by dividing the patients in groups: i) no endodontic lesions; ii) all endodontic lesions in teeth with root canal filling; and iii) untreated apical periodontitis (Liljestrand et al. 2016).

\section{Subgingival bacterial sampling, and bacterial and antibody analyses}

Pooled subgingival samples were taken from dentate subjects from the deepest pathologic periodontal pocket in each dentate quadrant as previously described (Mäntylä et al. 2013, Pradhan-Palikhe et al. 2013). In patients with no pockets exceeding $3 \mathrm{~mm}$ depth, the deepest possible site or site with most visible inflammation was selected for sampling. The checkerboard DNA-DNA hybridization assay for 78 oral bacterial species was performed as previously reported 
(Socransky et al. 2004, Pradhan-Palikhe et al. 2013). The detected species are given in a supplementary table (Table S1). The species were divided into gram-positive $(n=45)$ and gramnegative $(n=33)$ (Pietiäinen et al. 2019). The bacterial levels were logarithmically transformed and summed up.

The serum and saliva IgA- and IgG-class antibody levels against periodontitis-associated dysbiotic species were determined by ELISA and as described previously (Pussinen et al. 2002,2011, Akhi et al. 2017, Liljestrand et al. 2018). All together, 13 strains representing five species were used as antigens. The strains and the laboratory quality information are presented in Table S2.

\section{Statistical analysis}

The significance of the trends observed between patients classified according to the presence and severity of CAC were analyzed by Chi-square, ANOVA or Jonckheere-Terpstra. The association between the presence of CAC and CAD diagnosis, parameters from clinical and radiographical oral examination, bacterial and antibody data were analyzed with multiple logistic regression model adjusted for age, gender, dyslipidemia, diabetes, hypertension, and smoking (never/ever). Cox regression models were used to calculate the prediction models for cumulative survival in groups of CAC severity. The outcomes were CVD death and all-cause death and the models were adjusted for age, gender, dyslipidemia, diabetes, hypertension, and smoking (never/ever).

\section{Results}

Characteristics of the study population $(N=492)$ are shown in Table 1. A total of $102(20.7 \%)$ patients had detectable CAC in the panoramic radiographs; in $81(16.4 \%)$ patients the CAC was moderate and in $21(4.3 \%)$ severe. Age, hypertension, and smoking increased significantly with more severe CAC. Clinical, radiographic, and biochemical characteristics stratified according to CAC severity are presented in Table 2. While number of remaining teeth decreased, widened periapical spaces, apical rarefactions, root canal fillings, alveolar bone loss, periodontitis, and high level of gram-negative subgingival bacterial species increased with more severe CAC.

Frequencies of CAC according to CAD diagnosis and severity are presented in Figure $1 A$. Patients with chronic CAD $(28.1 \%)$ had more often CAC compared to patients with no CAD $(12.8 \%)$ or with ACS $(21.3 \%)(p=0.022)$. CAC severity correlated with CAD severity increasing from $12.0 \%$ in patients without stenosis into $16.0 \%, 24.7 \%$, and $32.5 \%$ in patients with 1,2 , and 3 stenosed arteries, respectively $(p=0.001)$ (Figure 1B). Those who died during the follow-up due to CVD $(35.8 \%)$ or other cause $(29.2 \%)$, had more frequently CAC at baseline than the survivors $(17.5 \%)(p=0.003)$ (Figure 1C).

This article is protected by copyright. All rights reserved 
The association of CAC with measured parameters was examined using logistic regression adjusted for age, gender, dyslipidemia, hypertension, diabetes, and smoking (Table 3). Presence of CAC was associated with mild and moderate to total alveolar bone loss, severe periodontal inflammation, severe apical periodontitis, root canal fillings, high level of gram-negative subgingival species, saliva IgG against dysbiotic species, severe CAD with stenosed arteries, and chronic CAD.

A total of $105(20.7 \%)$ of patients died during the 10 years of follow-up and $53(10.4 \%)$ deaths were because of CVD. Predicted cumulative survival of patients with moderate or severe CAC was analysed by using Cox regression adjusted for age, gender, dyslipidemia, hypertension, diabetes, and smoking (Figure 2). Moderate and severe CAC were associated with all-cause death with HRs $(95 \% \mathrm{Cl}, \mathrm{p})$ of $1.52(0.95-2.54,0.097)$ and 3.08 (1.58-6.06, 0.001), respectively. Severe CAC was associated with CVD-death with an HR of $3.43(1.42-8.25,0.006)$.

\section{Discussion}

In this relatively large population, it was possible to demonstrate associations of apical periodontitis, dysbiotic oral species, and immune response against them with the presence of CAC in panoramic dental radiographs. In addition, CAC, registered from dental radiographs, is associated with chronic, severe coronary artery disease and predicts increased risk for cardiovascular and all-cause mortality. The associations were independent of established CVD risk factors, including age, sex, hypertension, dyslipidemia, diabetes, and smoking.

Overall, $21 \%$ of patients in this cohort had detectable CAC, and in most patients $(16 \%)$ the finding was moderate, while in fewer patients $(4.3 \%)$ it was severe. The frequency of CAC was $21-28 \%$ in patients with coronary artery disease, which is lower than reported earlier in populations with medical conditions such as a recent stroke or AMI (34-37\%) (Friedlander et al. 1994, Gustafsson et al. 2020) or dilated cardiomyopathy (33\%) (Sung et al. 2004), but higher than in patients with type 2 diabetes (20\%) (Friedlander \& Maeder 2000), systemic risk factors (15\%) (Friedlander \& Golub 2006) or renal diseases (15-17\%) (Kansu et al. 2005). The prevalence of CAC in panoramic images in an asymptomatic middle-aged population is in the range of $2-5 \%$ (Mupparapu \& Kim 2007), while in this study population $12.8 \%$ of patients without significant CAD had detectable CAC. This prevalence is higher than the CAC observed in general population, because the population consisted of elderly patients seeking medical care for heart-related symptoms. However, this prevalence is considerably lower than in a recent study, where $28 \%$ of apparently healthy, elderly controls, who did not undergo angiography, had CAC (Gustafsson et al. 2020). In the present cohort, CAC was significantly associated with chronic CAD affecting all coronaries, while the association with ACS was not significant. The observations are in line with a

This article is protected by copyright. All rights reserved 
systematic review, where calcification measured with conventional modalities was usually found in more advanced lesions (Rennenberg et al. 2009).

Only a few studies have previously investigated associations between apical periodontitis and CAC. Friedlander et al. (2010) stated that CAC patients $(n=36)$ had more radiological signs of oral infections compared to controls $(n=36)$, although the statistical significance was diluted when periapical lesions were regarded separately in this rather small population (Friedlander et al. 2010). Another case-control study, including 20-40 -year-old males without advanced tooth loss, marginal periodontitis or major CVD risk-factors, found that patients with apical periodontitis $(n=60)$ had a significantly higher ultrasonically verified carotid artery intima-media thickness than controls $(n=60)$ (Chauhan et al. 2019). The present study is unique with a detailed radiological characterization of the endodontic status, and the results support an association between apical periodontitis and CAC.

Vigorous research is currently conducted regarding potential associations between apical periodontitis and CVD. Two recent systematic reviews and one meta-analysis all state similar conclusions: most studies suggest that apical periodontitis is an independent CVD risk-factor, although the level of evidence is low-moderate and biased by significant heterogeneity in design (Khalighinejad et al. 2016, Berlin-Broner et al. 2017, Aminoshariae et al. 2018). A positive crosssectional association has been proposed for apical lesions and CAD, defined inter alia as hospital diagnoses (Caplan et al. 2006, Pasqualini et al. 2012), computed tomography (Petersen et al. 2014), or coronary angiography (Costa et al. 2014, Liljestrand et al. 2016). The present study shows an independent association between severe apical periodontitis and CAC further suggesting a role of endodontic infections in atherosclerosis.

The oral cavity represents a point of entry into the blood circulation for pathogenic bacteria and their virulence factors. The antimicrobial strategies against microbial antigens include innate and adaptive immune responses and oxidative stress (Hernandez-Rios et al. 2017, Pietiäinen et al. 2019). Although the exact mechanisms are unclear, oral pathogens may mediate systemic inflammation contributing to the development of atherosclerosis (Pietiäinen et al. 2018). Increased amounts of salivary or subgingival periodontal pathogens and high levels of local and systemic antibodies produced against them are associated with the increased risk of both subclinical atherosclerosis and CAD (Pussinen et al. 2005, Desvarieux et al. 2005, Liljestrand et al. 2018). Infected root canals habit polymicrobial communities (Siqueira \& Rôças 2009), and similarly to the marginal periodontitis, the abundance of gram-negative species increase in endodontic lesions and surrounding tissues compared to the healthy situation (Dingsdag et al. 2016, Qian et al. 2019). The inflamed tissues produce high concentrations of local immunoglobulins, IgG and especially IgA (Greening \& Schönfeld 1980, Torres et al. 1994), and

This article is protected by copyright. All rights reserved 
most studies suggest at least a modest contribution of endodontic infections to the systemic inflammatory markers (Gomes et al. 2013, Garrido et al. 2019). It has been demonstrated that increasing amounts of gram-negative bacteria in subgingival plaque are associated with the severity of endodontic findings and that high levels of salivary $\lg G$ against dysbiotic bacteria are associated with apical periodontitis independently of marginal periodontitis (Pietiäinen et al. 2019). High levels of serum antibodies binding to $P$. endodontalis have also been demonstrated in patients with endodontic lesions (Liljestrand et al. 2016). In the present study, CAC is associated with high levels of gram-negative subgingival species and saliva IgG against dysbiotic species. This supports the current view that oral pathogens may have an impact on the systemic atherosclerosis risk. However, no significant association between CAC and serum IgG against dysbiotic species was found. Thus, the possible link between immune responses to oral pathogens and CAC remains to be elucidated.

The strengths of the study include detailed characterizations of the population and the long follow-up. Another follow-up study found an association between CAC and incident stroke and/or ischemic heart diseases (Bengtsson et al. 2019). Despite the general nature of detecting CAC in the present study and differences in effect sizes, the hazards for all-cause and CVD mortality were of the same magnitude (3.08 and 3.94) as in a systematic review (Rennenberg et al. 2009). In this review the presence of calcifications detected with any modality presented odds of 3.41 (95\% Cl 2.71-4.30) for any cardiovascular event, 4.62 (2.24-9.53) for all-cause mortality, and 3.94 (2.39-6.50) for CVD mortality (Rennenberg et al. 2009). The main limitation of the present study is that important features of carotid plaque, such as morphology (soft, echogenic, hard, irregular), precise location (adventitia, media), composition (stable, unstable), or degree of stenosis were not possible to determine. Moreover, it was not known whether the patients were symptomatic or not due to the presence of CAC. The cohort is composed of symptomatic patients undergoing coronary angiography and thus, the frequencies of positive CAC findings may be higher than in the general population. Further, endodontic disease was assessed only radiographically and the teeth with widened periapical spaces were not examined further.

\section{Conclusions}

Both dental and medical professionals should be aware of the potential of an association between CAC and oral infections. Physicians should suggest dental examinations to their cardiovascular patients since oral infections, dysbiotic bacteria, and immune response are associated with CAC. If $\mathrm{CAC}$ is visible in panoramic tomography during a dental examination, the patient should be referred for cardiovascular evaluation, since CAC may cause further diseases and severe complications predisposing to death.

This article is protected by copyright. All rights reserved 


\section{Acknowledgements}

The study was financially supported by the Academy of Finland, the Sigrid Juselius foundation, the European Endodontic Society, the Paulo foundation, the Finnish Dental Society Apollonia, the Yrjö Jahnsson foundation, and the Päivi and Sakari Sohlberg foundation. Professor Jaakko Peltola is acknowledged for his valuable help in analysing the radiographs.

\section{Conflict of interest statement}

The authors have stated explicitly that there are no conflicts of interest in connection with this article.

This article is protected by copyright. All rights reserved 


\section{References}

Akhi R, Wang C, Kyrklund M et al. (2017) Cross-reactive saliva IgA antibodies to oxidized LDL and periodontal pathogens in humans. Journal of Clinical Periodontology 44, 682-91.

Alves N, Deana NF, Garay I (2014) Detection of common carotid artery calcifications on panoramic radiographs: prevalence and reliability. International Journal of Clinical and Experimental Medicine 7, 1931-39.

Aminoshariae A, Kulild JC, Fouad AF (2018) The Impact of Endodontic Infections on the Pathogenesis of Cardiovascular Disease(s): A Systematic Review with Meta-analysis Using GRADE. Journal of Endodontics 44, 1361-6.

Beckstrom BW, Horsley SH, Scheetz JP et al. (2007) Correlation between carotid area calcifications and periodontitis: a retrospective study of digital panoramic radiographic findings in pretreatment cancer patients. Oral Surgery, Oral Medicine, Oral Pathology, Oral Radiology and Endodontics 103, 359-66.

Bengtsson VW, Persson GR, Renvert S (2014) Assessment of carotid calcifications on panoramic radiographs in relation to other used methods and relationship to periodontitis and stroke: a literature review. Acta Odontologica Scandinavica 76, 401-12.

Bengtsson VW, Persson GR, Berglund J, Renvert S (2016) A cross-sectional study of the associations between periodontitis and carotid arterial calcifications in an elderly population. Acta Odontologica Scandinavica 74, 115-20.

Bengtsson VW, Persson GR, Berglund J, Renvert S (2019) Carotid calcifications in panoramic radiographs are associated with future stroke or ischemic heart diseases: a long-term follow-up study. Clinical Oral Investigations 23, 1171-9.

Berlin-Broner Y, Febbraio M, Levin L (2017) Association between apical periodontitis and cardiovascular diseases: a systematic review of the literature. International Endodontic Journal 50, 847-59.

Buhlin K, Mäntylä P, Paju S et al. (2011) Periodontitis is associated with angiographically verified coronary artery disease. Journal of Clinical Periodontology 38, 1007-14.

Caplan DJ, Chasen JB, Krall EA et al. (2006) Lesions of endodontic origin and risk of coronary heart disease. Journal of Dental Research 85, 996-1000.

Carrotte P (2004) Endodontics: Part 3. Treatment of endodontic emergencies. British Dental Journal 197, 299-305.

Carter LC (2000) Discrimination between calcified triticeous cartilage and calcified carotid atheroma on panoramic radiography. Oral Surgery, Oral Medicine, Oral Pathology, Oral Radiology and Endodontics 90, 108-10.

This article is protected by copyright. All rights reserved 
Chauhan N, Mittal S, Tewari S, Sen J, Laller K (2019) Association of Apical Periodontitis with Cardiovascular Disease via Noninvasive Assessment of Endothelial Function and Subclinical Atherosclerosis. Journal of Endodontics 45, 681-90.

Costa TH, de Figueiredo Neto JA, de Oliveira AE, Lopes e Maia Mde F, de Almeida AL (2014) Association between chronic apical periodontitis and coronaryartery disease. Journal of Endodontics 40, 164-7.

Desvarieux M, Demmer RT, Rundek T, Boden-Albala B, Jacobs DRJR, Sacco RI, Papapanou PN (2005) Periodontal microbiota and carotid intima-media thickness: the Oral Infections and Vascular Disease Epidemiology Study (INVEST). Circulation 111, 576-82.

Dingsdag S, Nelson S, Coleman NV (2016) Bacterial communities associated with apical periodontitis and dental implant failure. Microbial Ecology in Health and Disease 27, 31307.

Friedlander AH, Manesh F, Wasterlain CG (1994) Prevalence of detectable carotid artery calcifications on panoramic radiographs of recent stroke victims. Oral Surgery, Oral Medicine, Oral Pathology 77, 669-73.

Friedlander AH (1995) Panoramic radiography: the differential diagnosis of carotid artery atheromas. Special Care in Dentistry 15, 223-7.

Friedlander AH, Maeder LA (2000) The prevalence of calcified carotid artery atheromas on the panoramic radiographs of patients with type 2 diabetes mellitus. Oral Surgery, Oral Medicine, Oral Pathology, Oral Radiology and Endodontics 89, 420-4.

Friedlander AH, Golub MS (2006) The significance of carotid artery atheromas on panoramic radiographs in the diagnosis of occult metabolic syndrome. Oral Surgery, Oral Medicine, Oral Pathology, Oral Radiology and Endodontics 101, 95-101.

Friedlander AH, Cohen SN (2007) Panoramic radiographic atheromas portend adverse vascular events. Oral Surgery, Oral Medicine, Oral Pathology, Oral Radiology and Endodontics 103, 8305.

Friedlander AH, Sung EC, Chung EM, Garrett NR (2010) Radiographic quantification of chronic dental infection and its relationship to the atherosclerotic process in the carotid arteries. Oral Surgery, Oral Medicine, Oral Pathology, Oral Radiology and Endodontics 109, 615-21.

Friedlander AH, El-Saden SM, Aghazadehsanai N, Chang TI, Harada ND, Garrett NR (2014) Association of calcified carotid atheromas visualized on panoramic images and aortic arch calcifications seen on chest radiographs of postmenopausal women. Journal of the American Dental Association 145, 345-51.

Friedlander AH, El Saden SM, Hazboun RC, Chang TI, Wong WK, Garrett NR (2015) Detection of carotid artery calcification on the panoramic images of post-menopausal females is significantly

This article is protected by copyright. All rights reserved 
associated with severe abdominal aortic calcification: a risk indicator of future adverse vascular events. Dentomaxillofacial Radiology 44, 20150094

Garoff M, Ahlqvist J, Levring Jäghagen E, Johansson E, Wester P (2016) Carotid calcification in panoramic radiographs: radiographic appearance and the degree of carotid stenosis. Dentomaxillofacial Radiology 45, 20160147.

Garrido M, Cárdenas AM, Astorga, J et al. (2019) Elevated Systemic Inflammatory Burden and Cardiovascular Risk in Young Adults with Endodontic Apical Lesions. Journal of Endodontics 45, $111-5$.

Gomes MS, Blattner TC, Sant'Ana Filho M et al. (2013) Can apical periodontitis modify systemic levels of inflammatory markers? A systematic review and meta-analysis. Journal of Endododontics 39, 1205-17.

Gomes BP, Berber VB, Kokaras AS, Chen T, Paster BJ (2015) Microbiomes of EndodonticPeriodontal Lesions before and after Chemomechanical Preparation. Journal of Endodontics 41, 1975-84.

Greening AB, Schönfeld SE (1980) Apical lesions contain elevated immunoglobulin G levels. Journal of Endodontics 12, 867-9.

Gustafsson N, Ahlqvist JB, Näslund U et al. (2018) Calcified carotid artery atheromas in panoramic radiographs are associated with a first myocardial infarction: a case-control study. Oral Surgery, Oral Medicine, Oral Pathology and Oral Radiology 125, 199-204.

Gustafsson N, Ahlqvist J, Näslund U et al. (2020) Associations among Periodontitis, Calcified Carotid Artery Atheromas, and Risk of Myocardial Infarction. Journal of Dental Research 99, 608.

Hansson GK, Libby P, Tabas I (2015) Inflammation and plaque vulnerability. Journal of Internal Medicine 278, 483-93.

Hernández-Ríos P, Pussinen PJ, Vernal R, Hernández M (2017) Oxidative Stress in the Local and Systemic Events of Apical Periodontitis. Frontiers in Physiology 8, 869.

Huumonen S, Suominen AL, Vehkalahti MM (2017) Prevalence of apical periodontitis in root filled teeth: findings from a nationwide survey in Finland. International Endodontic Journal 50, 229-36.

Kamak G, Yildirim E,Rencber E (2015) Evaluation of the relationship between periodontal risk and carotid artery calcifications on panoramic radiographs. European Journal of Dentistry 9, 4839.

Kansu O, Ozbek M, Avcu N, Gençtoy G, Kansu H, Turgan C (2005) The prevalence of carotid artery calcification on the panoramic radiographs of patients with renal disease. Dentomaxillofacial Radiology 34,16-9.

This article is protected by copyright. All rights reserved 
Khalighinejad N, Aminoshariae MR, Aminoshariae A, Kulild JC, Mickel A, Fouad AF (2016) Association between Systemic Diseases and Apical Periodontitis. Journal of Endodontics 42, 1427-34.

Khosropanah SH, Shahidi SH, Bronoosh P, Rasekhi A (2009) Evaluation of carotid calcification detected using panoramic radiography and carotid Doppler sonography in patients with and without coronary artery disease. British Dental Journal 207, discussion 162-3.

Lindy O, Suomalainen K, Mäkelä M, Lindy S (2008) Statin use is associated with fewer periodontal lesions: A retrospective study. BMC Oral Health 8, 16.

Liljestrand JM, Mäntylä P, Paju S et al. (2016) Association of Endodontic Lesions with Coronary Artery Disease. Journal of Dental Research 95, 1358-65.

Liljestrand JM, Paju S, Pietiäinen M et al. (2018) Immunologic burden links periodontitis to acute coronary syndrome. Atherosclerosis 268, 177-84.

Lockhart PB, Bolger AF, Papapanou PN et al. (2012) Periodontal disease and atherosclerotic vascular disease: Does the evidence support an independent association?: A scientific statement from the American Heart Association. Circulation 125, 2520-44.

Mupparapu M, Kim IH (2007) Calcified carotid artery atheroma and stroke: a systematic review. Journal of the American Dental Association 138, 483-92.

Mäntylä P, Buhlin K, Paju S et al. (2013) Subgingival Aggregatibacter actinomycetemcomitans associates with the risk of coronary artery disease. Journal of Clinical Periodontology 40, 583-90.

Nakib SA, Pankow JS, Beck JD et al. (2004) Periodontitis and coronary artery calcification: the Atherosclerosis Risk in Communities (ARIC) study. Journal of Periodontology 75, 505-10.

Pasqualini D, Bergandi L, Palumbo L et al. (2012) Association among oral health, apical periodontitis, CD14 polymorphisms, and coronary heart disease in middle-aged adults. Journal of Endodontics 38, 1570-77.

Petersen J, GlaßI EM, Nasseri P et al. (2014) The association of chronic apical periodontitis and endodontic therapy with atherosclerosis. Clinical Oral Investigations 18, 1813-23.

Pietiäinen M, Liljestrand JM, Akhi R (2019) Saliva and Serum Immune Responses in Apical Periodontitis. Journal of Clinical Medicine 8, 889

Pietiäinen M, Liljestrand JM, Kopra E, Pussinen PJ (2018) Mediators between oral dysbiosis and cardiovascular diseases. European Journal of Oral Sciences 126, 26-36.

Pradhan-Palikhe P, Mäntylä P, Paju S et al. (2013) Subgingival bacterial burden in relation to clinical and radiographic periodontal parameters. Journal of Periodontology 84, 1809-17.

Pussinen PJ, Vilkuna-Rautiainen T, Alfthan G, Mattila K, Asikainen S (2002) Multiserotype enzyme-linked immunosorbent assay as a diagnostic aid for periodontitis in large-scale studies. Journal of Clinical Microbiology 40, 512-8.

This article is protected by copyright. All rights reserved 
Pussinen PJ, Nyyssönen K, Alfthan G, Salonen R, Laukkanen JA, Salonen JT (2005) Serum antibody levels to Actinobacillus actinomycetemcomitans predict the risk for coronary heart disease. Arteriosclerosis, Thrombosis \& Vascular Biology 25, 833-8.

Pussinen PJ, Könönen E, Paju S et al. (2011) Periodontal pathogen carriage, rather than periodontitis, determines the serum antibody levels. Journal of Clinical Periodontology 38, 40511.

Qian W, Ma T, Ye M, Li Z, Liu Y, Hao P (2019) Microbiota in the apical root canal system of tooth with apical periodontitis. BMC Genomics 20,189.

Ravon NA, Hollender LG, McDonald V, Persson GR (2003) Signs of carotid calcification from dental panoramic radiographs are in agreement with Doppler sonography results. Journal of Clinical Periodontology 30, 1084-90.

Rennenberg RJ, Kessels AG, Schurgers LJ, van Engelshoven JM, de Leeuw PW, Kroon AA (2009) Vascular calcifications as a marker of increased cardiovascular risk: a meta-analysis. Vascular Health and Risk Management 5, 185-97.

Shin JM, Luo T, Lee KH (2018) Deciphering Endodontic Microbial Communities by Nextgeneration Sequencing. Journal of Endodontics 44, 1080-7.

Siqueira JF Jr, Rôças IN (2009) Diversity of endodontic microbiota revisited. Journal of Dental Research 88, 969-81.

Socransky SS, Haffajee AD, Smith C (2004) Use of checkerboard DNA-DNA hybridization to study complex microbial ecosystems. Oral Microbiology and Immunology 19, 352-62.

Sung EC, Friedlander AH, Kobashigawa JA (2004) The prevalence of calcified carotid atheromas on the panoramic radiographs of patients with dilated cardiomyopathy. Oral Surgery, Oral Medicine, Oral Pathology, Oral Radiology and Endodontics 97, 404-7.

Torres JO, Torabinejad M, Matiz RAR, Mantilla EG (1994) Presence of secretory IgA in human periapical lesions. Journal of Endodontics 20, 87-9.

Vaara S, Nieminen MS, Lokki ML et al. (2012) Cohort Profile: the Corogene study. International Journal of Epidemiology 41, 1265-71.

Yeluri G, Kumar CA, Raghav N (2015) Correlation of dental pulp stones, carotid artery and renal calcifications using digital panoramic radiography and ultrasonography. Contemporary Clinical Dentistry 6, S147-1.

This article is protected by copyright. All rights reserved 


\section{Figure legends}

Figure 1 Frequencies of carotid artery calcification (CAC) according to A) CAD diagnosis, B) CAD severity in coronary angiography, and $C$ ) death in the follow-up. The p-values are calculated by Chi-square test.

Figure 2 Predicted cumulative survival of the patients from A) all-cause and B) CVD death in the follow-up of 10 years (median 9.9, IQR 0.45, range 0.21-10.4). The survival curves are produced by Cox regression models adjusted for age, gender, hypertension, dyslipidemia, diabetes, and smoking (never/ever) and the HR with p-value is shown for patients with moderate and severe CAC compared to those without.

This article is protected by copyright. All rights reserved 
Table 1 Characteristics of subjects with and without carotid artery calcification (CAC).

\begin{tabular}{|c|c|c|c|c|c|}
\hline \multicolumn{2}{|l|}{ Variable } & $\begin{array}{l}\text { No CAC } \\
\mathrm{N}=390\end{array}$ & $\begin{array}{l}\text { Moderate CAC } \\
\qquad N=81\end{array}$ & $\begin{array}{c}\text { Severe CAC } \\
\qquad N=21\end{array}$ & \\
\hline \multirow[b]{2}{*}{ Age (years) } & & & Mean (SD) & & p-value ${ }^{1}$ \\
\hline & & $62.6(9.4)$ & $66.7(7.3)$ & $66.5(7.5)$ & $<0.001$ \\
\hline \multirow{2}{*}{ BMI $\left(\mathrm{kg} / \mathrm{m}^{2}\right)$} & & $27.8(5.0)$ & $28.1(5.3)$ & $29.0(4.9)$ & 0.298 \\
\hline & & & Median (IQR) & & p-value ${ }^{2}$ \\
\hline \multirow{2}{*}{$\begin{array}{l}\text { hs-CRP } \\
(\mathrm{mg} /)^{3}\end{array}$} & & $2.09(5.74)$ & $2.70(8.95)$ & $3.00(14.2)$ & 0.432 \\
\hline & & & $\mathbf{N}(\%)$ & & $p_{\text {-value }}{ }^{4}$ \\
\hline Gender & Males & $260(66.2)$ & $53(65.4)$ & $11(52.4)$ & 0.318 \\
\hline Dyslipidemia & & $313(80.7)$ & $65(80.2)$ & $18(85.7)$ & 0.727 \\
\hline Hypertension & & $237(60.8)$ & $62(77.5)$ & $16(76.2)$ & 0.005 \\
\hline liabetes & & $90(23.2)$ & $19(24.1)$ & $6(28.6)$ & 0.612 \\
\hline Smoking & Ever & $195(49.6)$ & $49(60.5)$ & $14(66.7)$ & 0.026 \\
\hline
\end{tabular}

${ }_{1}^{1}$ ANOVA, weighted linear terms; ${ }^{2}$ Jonckheere-Terpstra test; ${ }^{3}$ high-sensitivity C-reactive protein;

${ }^{4}$ Chi-square test, linear-by-linear association 
Table 2 Clinical, radiographic, and laboratory results of patients with and without carotid artery calcification (CAC).

\begin{tabular}{|c|c|c|c|c|c|}
\hline \multicolumn{2}{|l|}{ Variable } & $\begin{array}{l}\text { No CAC } \\
\mathrm{N}=390\end{array}$ & $\begin{array}{c}\text { Moderate CAC } \\
\qquad \mathrm{N}=81\end{array}$ & $\begin{array}{c}\text { Severe CAC } \\
\quad N=21\end{array}$ & \multirow[b]{2}{*}{ p-value ${ }^{1}$} \\
\hline & & \multicolumn{3}{|c|}{ Mean $(95 \% \mathrm{Cl})$} & \\
\hline \multicolumn{2}{|l|}{ Number of teeth } & $21.5(20.8-22.3)$ & $20.8(19.2-22.4)$ & $18.6(15.4-21.7)$ & 0.005 \\
\hline \multicolumn{2}{|l|}{ PPD 4-5 mm (\%) } & $12.9(11.6-14.3)$ & $15.1(11.8-18.3)$ & $14.7(7.7-21.7)$ & 0.178 \\
\hline \multicolumn{2}{|l|}{ PPD $\geq 6$ mm (\%) } & $3.24(2.42-4.06)$ & $3.48(1.61-5.35)$ & $7.15(0.33-14.0)$ & 0.357 \\
\hline \multicolumn{2}{|l|}{ BOP (\%) } & $37.5(35.5-39.4)$ & $37.3(33.0-41.5)$ & $41.4(32.2-50.5)$ & 0.602 \\
\hline \multicolumn{2}{|l|}{ Carious teeth } & $1.01(0.84-1.18)$ & $0.97(0.58-1.36)$ & $1.06(0.27-1.85)$ & 0.884 \\
\hline \multicolumn{2}{|l|}{ Widened periapical space } & $0.71(0.62-0.79)$ & $1.10(0.83-1.37)$ & $1.30(0.79-1.81)$ & $<0.001$ \\
\hline \multicolumn{2}{|l|}{ Apical rarefactions } & $0.34(0.24-0.43)$ & $0.48(0.27-0.69)$ & $0.50(0.03-0.97)$ & 0.048 \\
\hline \multicolumn{2}{|l|}{ Root canal fillings (RCF) } & $2.02(1.81-2.24)$ & $2.99(2.30-3.67)$ & $2.35(1.49-3.21)$ & 0.022 \\
\hline \multicolumn{2}{|c|}{ Saliva IgA against dysbiotic species (rlu/100 ms / 105) } & $3.48(3.23-3.72)$ & $4.16(3.32-5.00)$ & $3.75(2.42-5.08)$ & 0.200 \\
\hline \multicolumn{2}{|c|}{ Saliva IgG against dysbiotic species (rlu/100 ms / 105) } & $4.12(3.57-4.66)$ & $5.58(3.95-7.22)$ & $6.09(3.79-8.36)$ & 0.296 \\
\hline \multicolumn{2}{|c|}{ Serum IgA against dysbiotic species (EU) } & $3.24(3.02-3.47)$ & $3.51(2.99-4.03)$ & $3.29(2.46-4.12)$ & 0.365 \\
\hline \multicolumn{2}{|c|}{ Serum IgG against dysbiotic species (EU) } & $4.47(4.23-4.71)$ & $4.66(4.09-5.22)$ & $4.53(3.50-5.55)$ & 0.601 \\
\hline & & \multicolumn{3}{|c|}{$\mathbf{N}(\%)$} & p-value ${ }^{2}$ \\
\hline \multirow[t]{3}{*}{ Alveolar bone loss } & None & $103(27.5)$ & $8(10.8)$ & $0(0)$ & 0.001 \\
\hline & Mild & $160(42.7)$ & $41(55.4)$ & $10(50.0)$ & \\
\hline & Moderate to total & $112(29.9)$ & $25(33.8)$ & $10(50.0)$ & \\
\hline \multirow[t]{4}{*}{ Periodontal inflammation $^{3}$} & Low & $95(24.9)$ & $13(17.3)$ & $4(20.0)$ & 0.127 \\
\hline & Mild & $100(26.2)$ & $20(26.7)$ & $5(25.0)$ & \\
\hline & Moderate & $95(24.9)$ & $18(24.0)$ & $5(25.0)$ & \\
\hline & Severe & $91(23.9)$ & $24(32.0)$ & $6(30.0)$ & \\
\hline \multirow[t]{3}{*}{ Severity of apical periodontitis } & No endodontic lesions & $147(42.0)$ & $27(38.0)$ & $6(30.0)$ & 0.048 \\
\hline & Moderate & $158(45.1)$ & $26(36.6)$ & $10(50.0)$ & \\
\hline & Severe & $45(12.9)$ & $18(25.4)$ & $4(20.0)$ & \\
\hline \multirow[t]{3}{*}{ Treatment of apical periodontitis } & No endodontic lesions & $281(80.3)$ & $38(10.9)$ & $31(8.9)$ & 0.060 \\
\hline & All with RCF & $50(70.4)$ & $12(16.9)$ & $9(12.7)$ & \\
\hline & $\begin{array}{c}\text { Untreated apical } \\
\text { periodontitis }\end{array}$ & $15(75.0)$ & $1(5.0)$ & $4(20.0)$ & \\
\hline \multirow[t]{2}{*}{$\begin{array}{l}\text { Level of gram-positive } \\
\text { subgingival species }\end{array}$} & Below median & $171(51.4)$ & $28(43.1)$ & $9(47.4)$ & 0.318 \\
\hline & Above median & $162(48.6)$ & $37(56.9)$ & $10(52.6)$ & \\
\hline \multirow[t]{2}{*}{$\begin{array}{l}\text { Level of gram-negative } \\
\text { subgingival species }\end{array}$} & Below median & $175(52.7)$ & $25(38.5)$ & $6(31.6)$ & 0.009 \\
\hline & Above median & $157(47.3)$ & $40(61.5)$ & $13(68.4)$ & \\
\hline
\end{tabular}

${ }^{1}$ Jonckheere-Terpstra test for linear trend; ${ }^{2}$ Chi-square test, linear-by-linear association; ${ }^{3} \mathrm{PIBI}$ (periodontal inflammatory burden index) divided into quartiles

This article is protected by copyright. All rights reserved 
Table 3 Association between presence of carotid artery calcification (CAC) and periodontal, microbiological, and serological parameters.

\begin{tabular}{|c|c|}
\hline Logistic regression model & Odds ratio $(95 \% \mathrm{Cl})$ \\
\hline \multicolumn{2}{|l|}{ Confounders } \\
\hline Age (years) & $1.06(1.030-1.091)$ \\
\hline Male gender & $0.82(0.502-1.334)$ \\
\hline Dyslipidemia & $0.76(0.411-1.419)$ \\
\hline DM & $0.84(0.485-1.451)$ \\
\hline Hypertension & $2.28(1.315-3.963)$ \\
\hline Smoking (ever) & $1.92(1.179-3.121)$ \\
\hline \multicolumn{2}{|l|}{ Model 1} \\
\hline \multicolumn{2}{|l|}{ Alveolar bone loss } \\
\hline None & 1.00 \\
\hline Mild & $2.81(1.251-6.305)$ \\
\hline Moderate to total & $2.44(1.043-5.708)$ \\
\hline \multicolumn{2}{|l|}{ Model 2} \\
\hline Root canal fillings & $1.15(1.042-1.262)$ \\
\hline \multicolumn{2}{|l|}{ Model 3} \\
\hline \multicolumn{2}{|l|}{ Periodontal inflammation (PIBI) } \\
\hline Low & 1.00 \\
\hline Mild & $1.69(0.832-3.424)$ \\
\hline Moderate & $1.53(0.745-3.155)$ \\
\hline Severe & $2.23(1.110-4.473)$ \\
\hline \multicolumn{2}{|l|}{ Model 4} \\
\hline \multicolumn{2}{|l|}{ Severity of apical periodontitis } \\
\hline No endodontic lesions & 1.00 \\
\hline Moderate & $1.10(0.635-1.887)$ \\
\hline Severe & $2.25(1.148-4.410)$ \\
\hline \multicolumn{2}{|l|}{ Model 5} \\
\hline \multicolumn{2}{|l|}{ Treatment of apical periodontitis } \\
\hline No endodontic lesions & 1.00 \\
\hline Endodontic lesions with RCF & $1.69(0.826-3.467)$ \\
\hline Untreated endodontic lesions & $1.73(0.819-3.645)$ \\
\hline \multicolumn{2}{|l|}{ Model 6} \\
\hline \multicolumn{2}{|l|}{ Level of gram-positive species } \\
\hline Below median & 1.00 \\
\hline Above median & $0.80(0.407-1.584)$ \\
\hline \multicolumn{2}{|l|}{ Level of gram-negative species } \\
\hline Below median & 1.00 \\
\hline Above median & $2.73(1.359-5.497)$ \\
\hline
\end{tabular}

Model 7

This article is protected by copyright. All rights reserved 


\section{Model 8}

Saliva IgG against dysbiotic species (rlu/100 ms / 105)

$1.05(1.005-1.096)$

\section{Model 9}

Serum IgA against dysbiotic species (EU)

$0.98(0.871-1.108)$

\section{Model 10}

Serum IgG against dysbiotic species (EU)

$0.99(0.883-1.103)$

\section{Model 11}

CAD severity in angiography

None/mild 1.00

1 stenosed artery $\quad 1.45(0.718-2.918)$

2 stenosed arteries $\quad 1.72(0.850-3.471)$

3 stenosed arteries $\quad 2.58(1.356-4.902)$

\section{Model 12}

CAD diagnosis

No significant CAD $\quad 1.00$

Chronic CAD

$2.13(1.153-3.930)$

ACS

$1.68(0.893-3.177)$

The twelve logistic regression models were adjusted for the covariates above (confounders). Significant effect sizes are bolded.

This article is protected by copyright. All rights reserved 


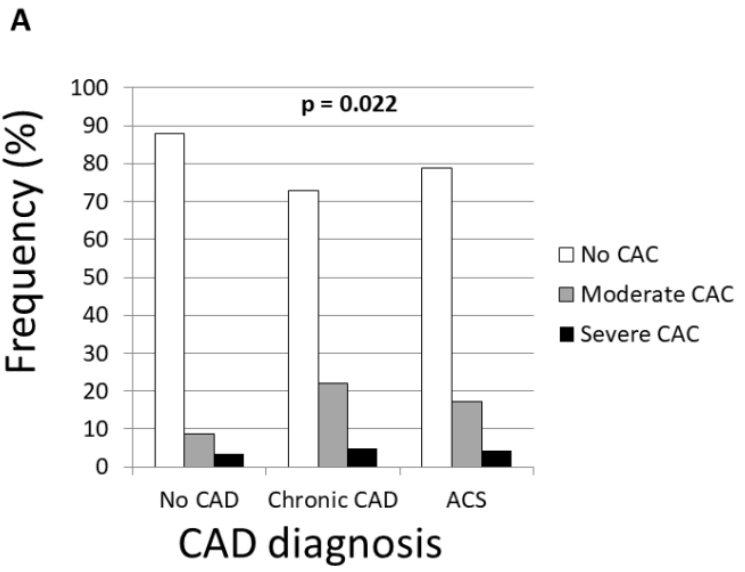

iej_13394_f1a.tif

This article is protected by copyright. All rights reserved 


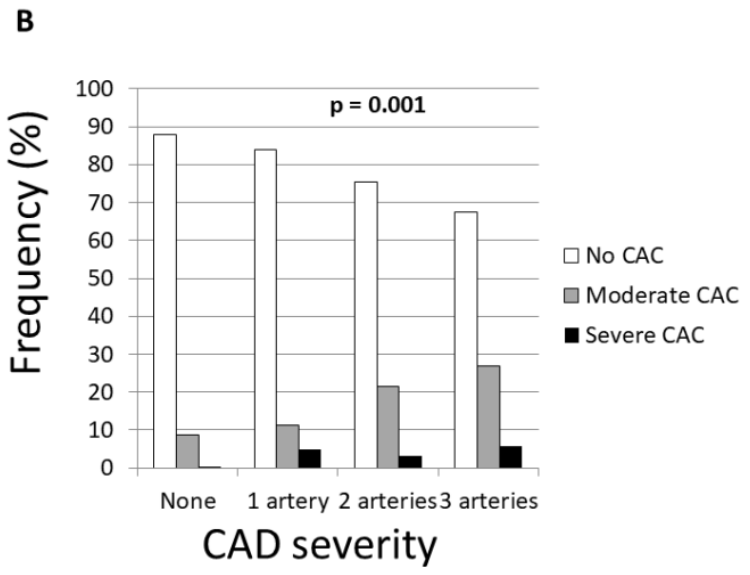

iej_13394_f1b.tif

This article is protected by copyright. All rights reserved 


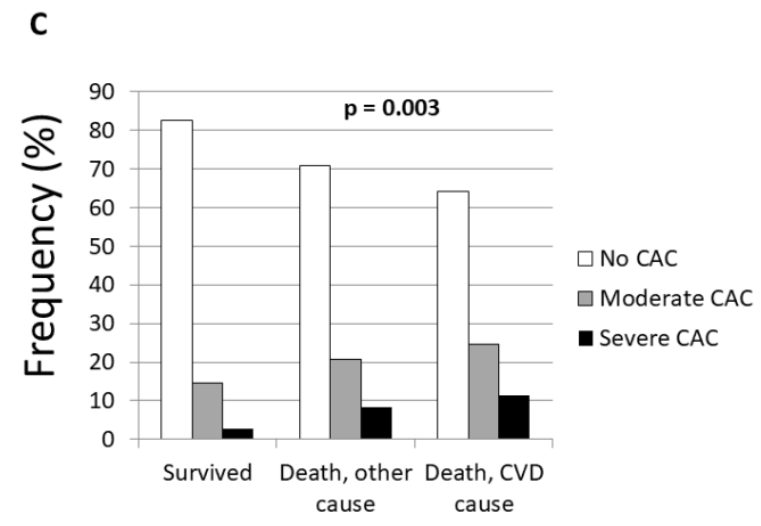

iej_13394_f1c.tif

This article is protected by copyright. All rights reserved 
A

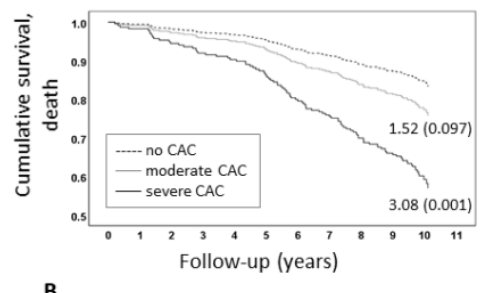

B

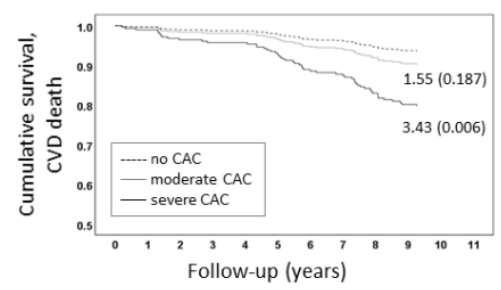

iej_13394_f2.tif

This article is protected by copyright. All rights reserved 